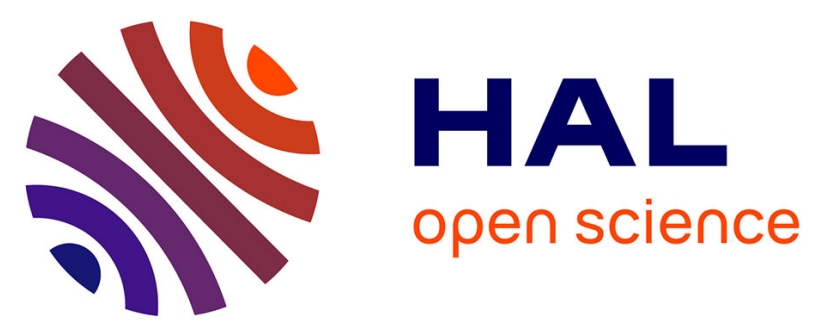

\title{
Surface film morphology (AFM) and chemical features (XPS) of cycled V2O5 thin films in lithium microbatteries
}

Benoit Fleutot, Hervé Martinez, Brigitte Pecquenard, Jean-Bernard Ledeuil, Alain Levasseur, Danielle Gonbeau

\section{To cite this version:}

Benoit Fleutot, Hervé Martinez, Brigitte Pecquenard, Jean-Bernard Ledeuil, Alain Levasseur, et al.. Surface film morphology (AFM) and chemical features (XPS) of cycled V2O5 thin films in lithium microbatteries. Journal of Power Sources, 2008, 180 (2), pp.836-844. 10.1016/j.jpowsour.2008.02.080 . hal-00280759

\section{HAL Id: hal-00280759 \\ https://hal.science/hal-00280759}

Submitted on 21 May 2008

HAL is a multi-disciplinary open access archive for the deposit and dissemination of scientific research documents, whether they are published or not. The documents may come from teaching and research institutions in France or abroad, or from public or private research centers.
L'archive ouverte pluridisciplinaire HAL, est destinée au dépôt et à la diffusion de documents scientifiques de niveau recherche, publiés ou non, émanant des établissements d'enseignement et de recherche français ou étrangers, des laboratoires publics ou privés. 


\title{
Surface film morphology (AFM) and chemical features (XPS) of cycled $\mathrm{V}_{2} \mathrm{O}_{5}$ thin films in lithium microbatteries
}

\author{
B. Fleutot, H. Martinez, B. Pecquenard, J.B. Ledeuil, A. Levasseur and D. Gonbeau
}

\section{Introduction}

The increasing need for highly efficient power sources suitable for small and light electronic devices has led researchers to develop thin film electrodes for lithium microbatteries. Intense research efforts are currently undertaken in order to improve the performances of positive electrode materials usable in these systems [1], [2] and [3].

Among the transition metal oxides, vanadium pentoxide V2O5 is a promising candidate as positive electrode material for lithium secondary microbatteries. Indeed, this material presents a layered structure, a high energy density [4] and [5] and a possibility to insert 3 Li per V2O5 leading to an overall faradic capacity close to $420 \mathrm{Ah} \mathrm{kg-1}$ [6]. Furthermore, various oxidation states for the vanadium exist and this material is easily prepared as a thin film using various methods such as CVD [7], PVD [8], spin-coating [9], etc. In a previous study, we have reported on the preparation and the characterization of V2O5 thin films deposited by rf sputtering from a V2O5 target under various Ar/O2 atmospheres and total gas pressures [10].

Even if the discharge capacity is very attractive, there is a real challenge for enhancing the performances especially in terms of cycling stability to fit the requirements of microelectronic systems. Indeed, previous studies on crystallized vanadium pentoxide thin films have shown a continuous capacity fading over cycling in the following wide potential window [3.7-1.5 V/Li] [10]. The capacity fading may originate upon cycling from repeated structural transformations that can induce fatigue damage to the microstructure, but also from partial irreversibility of the redox processes occurring inside crystallized V2O5 thin films for this potential range as it was clearly evidenced by a previous XPS study [11]. Finally, this fading could also result from the formation of a passivation layer solid electrolyte interface (SEI)-like during the discharge that consumes a part of electrons and so induces an increase of the electrode impedance as well as the overall battery resistance. The SEI formation is well established on negative electrode such as lithium or graphite and was widely explored in terms of chemical composition, electronic properties, structure, morphology, etc. [12], [13] and [14]. Even if there was some controversy about the possibility of such surface films formation on positive electrode material, this formation is now accepted by a large number of researchers in the battery field community. However, its composition as its structure remains a controversial topic. Our previous studies achieved by XPS before mechanical erosion [15] have evidenced the formation of a SEI-like 
layer concomitant with a disappearance of the vanadium $V 2 p$ core peak. Few AFM studies have been done to study the morphology of the passivation layer [16] and [17]. In many cases, the resolution of the images is too low to allow a clear observation of the latter. One of the first in situ AFM imaging of the surface films formation on V2O5 cathodes (prepared by thermal evaporation), cycled in LiPF6 (EC:DMC 1/1) in the reversible potential range, was achieved by Cohen and Aurbach [16]. After the first discharge, he has noticed the appearance of some nanosize round shaped grains on the boundaries of V2O5 particles that remain in the deintercalated stage. Aurbach has attributed this deposit to decomposition products of LiPF6, mainly LiF, because he does not observe such phenomenon using LiClO4 solutions. Marcus and co-workers [17] was one of the first to combine XPS spectroscopy and AFM analyses in order to characterize the SEI layer formation. But the pristine material, which was prepared by thermal oxidation of metallic vanadium, has a non-homogeneous composition all over the thickness with a gradual evolution from $V$ to $V 205$ including $V n O 2 n+1$ type mixed oxides. In addition, the thin film ageing was done by using cyclic voltammetry, in conditions that do not really correspond to a normal utilization of a positive electrode in a microbattery. The aim of this work is to investigate the capacity fading highlighted for crystallized V205 thin films prepared by rf sputtering by combining the complementary XPS and AFM analyses at various stages of the first discharge/charge galvanostatic cycle as well as for following cycles. A particular attention will be devoted to the SEI study by XPS in order to get qualitative (presence or not) and quantitative informations (composition, thickness evolution, etc.). Furthermore, in order to get accurate informations concerning the morphology of the SEI, systematic thorough investigations have been achieved by AFM inside a glove box, including a detailed preliminary study consisting to identify the accurate analysis conditions leading to images with the best definition.

\section{Experimental details}

\subsection{Samples preparation}

Vanadium pentoxide thin films have been prepared by radio frequency magnetron sputtering in a chamber (PLASSYS) connected to an argon-filled glove box. The target was prepared by cold pressing from a V2O5 powder (99.99\%) purchased from Aldrich and sintering at $600{ }^{\circ} \mathrm{C}$ for $6 \mathrm{~h}$. Before each deposition, vacuum was applied in the chamber until the pressure was less than 10-4 Pa, and a presputtering has systematically been achieved during $1 \mathrm{~h}$. All thin films were deposited at room temperature with no intentional heating of the stainless steel substrates, with a nominal rf power density of $2.55 \mathrm{~W} \mathrm{~cm}-2$ and a target-to-substrate distance equal to $8 \mathrm{~cm}$. The sputtering was performed under a mixture of pure argon (99.999\%) and pure oxygen (99.99\%) with a total pressure of $1 \mathrm{~Pa}$ and an oxygen partial pressure of $14 \%$ (corresponding to an argon/oxygen ratio equal to $86 / 14)$. In order to avoid any surface contamination of the films, all samples were handled in an argon- 
filled glove box and transferred to the different apparatus used for characterization through airtight containers.

\subsection{Galvanostatic cycling}

The electrochemical characterization has been achieved galvanostatically using crystallized vanadium pentoxide thin films as the positive electrode, metallic lithium as the negative electrode, both being separated by a glass fiber soaked with a liquid electrolyte (1 M LiPF6 in a mixture of PC, EC, DMC, DEC in a ratio $4: 2: 9: 5)$. The current density was fixed to $20 \mu \mathrm{A} \mathrm{cm}-2$ and the potential window was [3.7$1.5 \mathrm{~V} / \mathrm{Li}$. This large potential window was chosen in order to amplify the redox processes and the passivation phenomenon, even if it does not correspond to the best conditions for an optimized cycling. Prior to the analyses, the lithiated samples were washed with diethylcarbonate (DEC) in order to remove the remaining lithium salt that could be present at the surface.

\subsection{X-ray photoelectron spectroscopy}

X-ray photoelectron spectroscopy analyses were carried out with a Surface Science Instruments Spectrometer (model 301) using a focused and monochromatized Al K* radiation (1486.6 eV) (diameter of the irradiated area $=600 \mu \mathrm{m}$ ). The spectrometer was calibrated using the photoemission

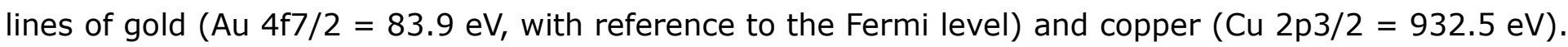
The Au 4f7/2 full width at half maximum (FWHM) was $0.86 \mathrm{eV}$. The peaks were recorded with constant pass energy of $50 \mathrm{eV}$. All the samples were fixed on the sample holders in a glove box directly connected to the introduction chamber of the spectrometer. The XPS analyses were carried out onto the as-deposited thin film and ex situ at different stages of the cycling. They were performed before mechanical erosion in order to characterize the passivation phenomena and after mechanical erosion under ultra high vacuum in order to characterize the redox processes. The experimental curves were fitted with a combination of Gaussian (80\%) and Lorentzian (20\%) functions using a minimum number of components.

\subsection{Atomic force microscopy}

AFM imaging was performed with a MultiMode Scanning Probe Microscope (MM-SPM) from Veeco society and a controller Nanoscope IIIA and Quadrex. A preliminary study has been done by optimising the working conditions allowing to get an optimal definition of every image details. The first analysis in "contact" mode evidenced a less good definition of the topography compared with the tapping mode. Indeed, in contact mode, the tip is constantly in touch with the surface of the sample. This leads side movement of the probe during the scanning. This phenomenon called "friction" perturbs strongly the image resolution and forbid quantitative analysis. Moreover, different tips were tested to find a good compromise between a weak radius of curvature allowing a good resolution and a sufficient inflexibility for the weakest possible abrasion during scanning of the probe. Taking into account these preliminary 
results, all AFM images were acquired in intermittent contact mode (tapping) to obtain topographic (with a scanning frequency from 0.4 to $0.8 \mathrm{~Hz}$ ), phase and deflection (error signal) images using a MPP-11100 Veeco probe which has a quoted probe radius of curvature lower than $10 \mathrm{~nm}$. A phosphorus (n) doped Si with a force of 20-80 N m-1 at a resonance frequency of about $290 \mathrm{kHz}$ was employed. This instrument was used in a glove box under argon atmosphere with oxygen and water levels lower than $1 \mathrm{ppm}$ to avoid surface contamination. Samples were packaged in airtight containers under argon during their transfer between the various devices of analyses in order to disrupt the chemical composition of our samples.

Quantitative analyses have been done using the pertinent $\mathrm{Rq}$ parameter which is the root mean square average of height deviations taken from the mean data plane, expressed as: $\mathrm{Rq}=\sqrt{\Sigma(\mathrm{Zi})^{2} / n}$ where $\mathrm{Zi}$ is the current $Z$ value, $\mathrm{n}$ is the number of points considered (typically 30 ). The $\mathrm{Rq}$ value is not corrected for tilt in the plane of the data. It represents a suitable term for surface roughness, derived from ASME B46.1 ("Surface texture:Surface roughness, waviness and Lay" available from the American Society of Mechanical engineers). To complete the quantitative analysis, the size of plate sides has been evaluated by taking into account 30 measurements with a typical deviation of $2 \mathrm{~nm}$.

\section{Results and discussion}

\subsection{Electrochemical results}

Some crystallized $\mathrm{V}_{2} \mathrm{O}^{5}$ thin films deposited onto a stainless steel substrate have been electrochemically tested as positive electrode in a lithium battery cell using galvanostatic cycling. In Fig. 1a is represented the first galvanostatic cycle. The first discharge curve evidences a stepwise discharge with four plateaus, respectively, at 3.4, 3.2, 2.3 and $1.9 \mathrm{~V}$, as it was previously observed for V2O5 bulk material [18], [19] and [20] and attributed to the different structural phases transitions occurring during lithium intercalation: $* \rightarrow \varepsilon, \varepsilon \rightarrow \delta, \delta \rightarrow \gamma$ and $Y \rightarrow \omega$. Each plateau was ascribed to a two phases domain displaying the successive structural modifications of the material induced by the lithium insertion. Fig. 1b displays the evolution of the discharge capacity as a function of the number of cycles. A strong capacity loss around $25 \%$ is observed for the first cycle. Then a continuous capacity fading occurs for following cycles with a slightly more pronounced decrease after the 10th cycle.

\subsection{XPS and AFM results at the first cycle}

\subsubsection{XPS}

First, we can briefly remind previous results [11] concerning the redox processes which were systematically studied at different stages of the first cycle after erosion under ultra high vacuum: The first discharge is characterized by a partial reduction of V5+ ions (the formal degree for vanadium ions present into $\mathrm{V}_{2} \mathrm{O}_{5}$ ) into $\mathrm{V}^{4+}$ and further " $\mathrm{V}^{3+}$ " ions for a potential equal to $1.5 \mathrm{~V} / \mathrm{Li}$ (Table 1 ). Each 
oxidation degree attribution are related to reference compounds: $\mathrm{V}_{2} \mathrm{O}_{5}, \mathrm{VO}_{2}$ and $\mathrm{V}_{2} \mathrm{O}_{3}[11]$. Note that the bulk material $\mathrm{V}_{2} \mathrm{O}_{5}$ exhibits a similar reduction phenomenon. The non-usual observation at the same time of three oxidation states for a transition metal oxide could be explained by the presence of several possible nonsymmetrical crystallographic sites. We have also considered a disproportionation of two V4+ ions into "V3+" and V5+, considering that the respective percentages of these two last species are close at the end of the discharge. At the end of the first charge, a partial reoxidation occurs; the "V3+" peak disappears, while the intensity of the V4+ peak decreases to $20 \%$ and the amount of $\mathrm{V} 5+$ reaches $80 \%$ (Table 1 ). The evolution of the $\mathrm{O}$ 1s XPS core peak does not allow to conclude concerning the eventual role played by the oxygen ions in the redox mechanism. These results have suggested that the redox mechanisms are not fully reversible, as the $V 2 \mathrm{p}_{3 / 2}$ core peak was not similar to the one of the as-deposited sample (Table 1), and this evolution could be correlated to the capacity loss observed for the first cycle (Fig. 1b). Beside these previous XPS studies, thorough analyses were systematically carried out to probe the cathode/electrolyte interface. As we have noticed, this interface, which is commonly encountered for anode materials, seems to play a major role regarding the electrochemical performances in term of capacity loss during the first cycle and cycling stability. The XPS semi-quantitative analyses display that the vanadium amount decreases upon the discharge $(0.50 \%$, vanadium percentage) and increases back upon the charge (11.40\%) (Fig. 2). As XPS probes $\approx 50 \AA$, these results seem to indicate that an interface is growing upon the discharge and is partially dissolved during the charge. It is to be noted that the $\mathrm{V} / \mathrm{O}\left(\mathrm{O}\right.$ 1s component from $\mathrm{V}_{2} \mathrm{O}_{5}$ ) ratio is constant into the $\mathrm{V}_{2} \mathrm{O}_{5}$ thin film. An analysis of the $\mathrm{O}$ 1s core peaks (Table 2, Fig. 3a) confirms the previous results. At the end of the first discharge, the peak characteristic of $\mathrm{V}_{2} \mathrm{O}_{5}(01: 530.2 \mathrm{eV}$, Table 2) is almost not detectable and we observed two components $\mathrm{O} 2$ and $\mathrm{O} 3$, respectively located at 531.8 and $533.3 \mathrm{eV}$, which can be attributed to the formation of SEI species. These components are still present at the end of the first charge but $\mathrm{O} 1$ becomes once again a main component of the $\mathrm{O} 1 \mathrm{~s}$ signal even if $\mathrm{O} 2$ remains the major one. Hence, the use of two independent probes ( $\mathrm{V} 2 \mathrm{p}$ and $\mathrm{O}$ 1s core peaks) evidences the formation and the partial dissolution of a layer at the interface between the $\mathrm{V}_{2} \mathrm{O}_{5}$ positive electrode thin films and the liquid electrolyte. The $\mathrm{C}$ 1s core peak (Table 3, Fig. 3b) provides valuable information regarding the nature of this layer and should be jointly analyzed with the O 1s signal (Fig. 3a). For the pristine material, two components (C1 and C2) located at 285 and $286.5 \mathrm{eV}$ are evidenced (Table 3). The first one is assigned to hydrocarbon contamination and to carbon atoms bound only to $\mathrm{C}$ or $\mathrm{H}$ atoms. The second one is attributed to carbon atoms in a one-oxygen environment $\mathrm{C}-\mathrm{O}$. At the end of the discharge, the main component $\mathrm{C} 4$ located at $290.1 \mathrm{eV}$, characteristic of carbon atoms in a three-oxygen environment, reveal the presence of carbonate species. These species could be $\mathrm{Li}_{2} \mathrm{CO}_{3}$ and/or lithium alkyl carbonates $\mathrm{ROCO}_{2} \mathrm{Li}$, frequently observed at anode/electrolyte interface [21], [22] and [23] and resulting from the reduction of organic solvent from 
the electrolyte. Note that the presence of $\mathrm{ROCO}_{2} \mathrm{Li}$ should result in a peak of equal intensity at $286.5 \mathrm{eV}$ (C2 peak), these species presenting a number of carbon atoms bound to three oxygen atoms $\left(\mathrm{R}-\mathrm{CH}_{2}-\mathrm{OCO} 2 \mathrm{Li}\right)$ equal to the number of carbon bound to one oxygen $\left(\mathrm{R}-\mathrm{CH}_{2}-\mathrm{OCO}_{2} \mathrm{Li}\right)$. The low intensity of the C2 peak allows to mainly assign the peak at $290.1 \mathrm{eV}$ to lithium carbonate. The corresponding oxygen atoms from $\mathrm{Li}_{2} \mathrm{CO}_{3}$, located at $531.8 \mathrm{eV}$, lead to the $\mathrm{O} 2$ component, which represents the main contribution of the $\mathrm{O} 1 \mathrm{~s}$ signal at this potential stage. The peak $\mathrm{C} 2$ could be also explained by the presence of ROLi or oligomeric species of polyethylene oxide PEO $\left(-\mathrm{CH}_{2}-\mathrm{CH}_{2}-\mathrm{O}-\right)_{n^{\prime}}$ for which all carbon atoms are in a one-oxygen environment. These last species may come from a ringopening mechanism of the solvent EC (ethylcarbonate), leading to the formation of $\mathrm{CO}_{2}$ according to the following reaction [24]: $n\left(\mathrm{CH}_{2} \mathrm{O}\right)_{2} \mathrm{CO} \rightarrow\left(-\mathrm{CH}_{2}-\mathrm{CH}_{2}-\mathrm{O}-\right)_{n}+n \mathrm{CO}_{2}$

The presence of these species is consistent with the presence of an $\mathrm{O} 3$ component located at $533.3 \mathrm{eV}$ [24]. Note that an additional weak component C3 (4\%) at $288.7 \mathrm{eV}$ was necessary to fully interpret the shape of this $\mathrm{C}$ 1s spectrum (see Table 3). This component can be assigned to carbon atoms in a twooxygen environment, and could be explained by a small amount of oxalates at the surface. Their formation mechanism has been discussed in a previous work [25], and could be due to solvents decomposition reactions leading to the formation of $\mathrm{O}_{-} \mathrm{C}=\mathrm{O}$ species. At the level of the $\mathrm{O} 1 \mathrm{~s}$ signal, oxygen atoms belonging to oxalates have a signal located at the same binding energy than the one for $\mathrm{Li}_{2} \mathrm{CO}_{3}$ species (O2 component). At the end of the charge, the peak characteristic of lithium carbonate (C4) is not still detectable anymore, which is also confirmed by the intensity decrease of the $\mathrm{O} 2$ component (i.e. the relative percentage, Table 2). We observe the presence of $\mathrm{C} 2$ and $\mathrm{C} 3$ components, respectively assigned to PEO/ROLi and oxalates in addition to the contamination peak. Beside core peak investigations, valence band (VB) analysis of $\mathrm{V}_{2} \mathrm{O}_{5}$ during the first cycle (Fig. 4) may be a powerful experimental tool for a better characterization of electrodes' surfaces. The VB of the reference $\mathrm{Li}_{2} \mathrm{CO}_{3}$ is added for comparison. For the pristine material, the valence band spectrum presents two main bands. On the high binding energy side, a single band centered at $22 \mathrm{eV}$ corresponds to the specific ionization of the oxygen $2 \mathrm{~s}$ orbitals. The broad band at lower binding energies (7.5-2 eV) is associated with orbitals mainly involving $02 \mathrm{p}$. This result is in agreement with the formal oxidation degree +5 for vanadium atoms and thus empty $3 d$ orbitals ( $d^{0}$ configuration). At the end of the first discharge, the valence band spectrum is similar to thus of the reference $\mathrm{Li}_{2} \mathrm{CO}_{3}$, characterized by a massif located at $6.1 \mathrm{eV}$ and two narrow bands at 10.8 and $12.9 \mathrm{eV}$. These bands disappear at the end of the first charge, in agreement with the $\mathrm{Li}_{2} \mathrm{CO}_{3}$ species dissolution, and the two main bands of the pristine 
material are recovered. However, we note just below the Fermi level $\left(E_{\mathrm{F}}\right)$ a small band, related to vanadium 3d orbitals. This result, clearly identified for the $\mathrm{VO}_{2}$ reference, confirms the core peak analysis for the thin film at the end of the charge (Table 1) and the presence of the formal oxidation degree +4 for vanadium ions which reflects the only partial reversibility of the redox process. On the whole, the formation and dissolution process is highlighted and mainly concerned $\mathrm{Li}_{2} \mathrm{CO}_{3}$ species. Cohen and Aurbach have indicated that a deposit is formed and could be attributed to the decomposition products of $\mathrm{LiPF}_{6}$, mainly to LiF because they do not observe any SEI formation using $\mathrm{LiClO}_{4}$ as a salt [16]. Note that only a very few atomic percentage (less than $2 \%$ ) of fluorine and phosphorous was revealed by our XPS analyses at the surface of the thin layer. Nevertheless, Aurbach has proposed a mechanism showing the possible formation of $\mathrm{Li}_{2} \mathrm{CO}_{3}$ and $\mathrm{ROCO}_{2} \mathrm{Li}$ on the surface films of the cathodes through secondary reactions of HF with the surface species on the negative electrode. It is necessary to underline that the presence of such species at upper potentials than those required for a reduction of carbonate solvents could be interpreted either by a process catalyzed in surface (as similar results were obtained for $\mathrm{TiO}_{y} \mathrm{~S}_{z}$ oxysulfide thin films [26]) or by a migration of these species formed at the surface of the negative electrode via the electrolyte which would layout at the positive electrode.

\subsubsection{AFM}

Fig. 5 presents the SEM image of the as-deposited $\mathrm{V}_{2} \mathrm{O}_{5}$ thin film (a) and the AFM topographic images of thins films at different stages of the first cycle: the pristine material (b), at the end of the discharge $(1.5 \mathrm{~V} / \mathrm{Li})(\mathrm{c})$ and at the end of the charge (3.7 V/Li) (d). The AFM image of the as-deposited material exhibits tangled plates oriented in a direction perpendicular to the substrate, in good agreement with the SEM image revealing a porous thin film constituted of numerous tangled rods. This result is also consistent with the X-ray diagram [10] displaying a preferential orientation with the $c$-axis perpendicular and the $(a, b)$-plane parallel to the substrate surface. The average size of plate sides (thickness) could be estimated to $80 \mathrm{~nm}$ (Table 4).

At the end of the first discharge (1.5 V/Li, Fig. 5c), the plates are no more detectable but aggregates are present on the top of the film. This first result could be correlated to the XPS analyses, particularly to the weak vanadium and oxygen (from the material) percentages detected at the end of the discharge (Fig. 2). So, at this stage, these aggregates constitute the interfacial layer and are mainly constituted by $\mathrm{Li}_{2} \mathrm{CO}_{3}$ species. XPS analyses point out that between the end of the 1st discharge and the end of the 1st charge, the lithium carbonate species are dissolved, nevertheless a few percentage of oxalate and PEO ones are still present on the surface. The topographic image acquired at the end of 
the charge (Fig. $5 d$ ) exhibits the typical plates of $\mathrm{V}_{2} \mathrm{O}_{5}$ covered with a residual deposit. Indeed, the thickness of plates rises by 20\% ( 100-105 nm) and the roughness Rq (Table 4$)$ decreases from $160 \mathrm{~nm}$ (for the as-deposited thin film) to $136 \mathrm{~nm}$ (for the thin film at the end of the 1st cycle). The decrease of the surface roughness is characteristic of a residual deposit which partially filled up surface "hollows". These images allow to characterize the morphological changes during the first cycle and display the formation and the partial dissolution of the interfacial layer. It is striking to note that the AFM observations are totally consistent with XPS results. Beyond the partial reversibility of the redox process, the $25 \%$ of capacity loss noticed at the end of the first galvanostatic cycle (Fig. 1) could also be explained by the SEI formation that consumes some electrons and some lithium ions for its growth.

\subsection{XPS and AFM results during cycling}

To understand the behavior of the thin film during cycling, it is not only necessary to follow the redox processes occurring during lithium insertion into thin films, but also to thoroughly investigate the interfacial layer evolution. After the $10^{\text {th }}$ discharge, we observe the presence of three oxidation degrees for vanadium, in similar proportions compared to the first discharge (Table 1). This result highlights a quite stable reduction process during the first ten cycles, in agreement with the discharge capacity curve (Fig. 1). After the 10th charge, we observe the presence of the components associated with $\mathrm{V}^{5+}$ and $\mathrm{V}^{4+}$ in a ratio $61 / 39$ exhibiting a weak degradation of the reversibility compared to the first charge (initial ratio: 66/34). During the 30th discharge, the proportion of the $\mathrm{V}^{3+}$ is reduced to $21 \%$, reflecting a weaker reduction at the 30th cycle. So, from the tenth cycle, there is a degradation of the reduction process of the material which can be at the origin of the discharge capacity fading (about $11.5 \%$ ) between the tenth and the thirtieth cycle (Fig. 1). During the charge, the redox process is slightly less reversible (the proportion of $\mathrm{V}^{5+}$ and $\mathrm{V}^{4+}$ is, respectively, equal to $57 \%$ and $43 \%$ ).

From a quantitative point of view, if we consider the vanadium atoms percentage showing a decrease from the first to the 30th discharge (Fig. 2), either the dissolution process of the SEI is less and less effective or the dissolution is constant during cycles but the thickness of the interfacial film adhering to the positive electrode increases due to the accumulation of residual deposit. The chemical composition and relative percentage of SEI species present at the 10th cycle is very similar to the first one. The main differences are observed for the 30th cycle: at the level of the $C 1$ spectra, the intensity of the components previously assigned to alkyl carbonate or/and polyethylene oxide and oxalate, respectively located at 286.5 and $288.7 \mathrm{eV}$ increase (Fig. 6a, Table 5). This phenomenon is underlined in discharge and in charge as these species are more and more present on the surface, in contrary to lithium carbonates of which the relative percentage (during discharge) and the dissolution process appear identical over cycles. This result is confirmed by the analysis of the $\mathrm{O} 1 \mathrm{~s}$ core peak at the thirtieth cycle (Fig. 6b, Table 6): at the end of the thirtieth discharge, the intensity of the component 03, related to 
oxygen atoms from PEO and/or ROLi species increases compared to the first and the tenth discharge (Table 2 and Table 6). Nevertheless, the $\mathrm{O} 2$ component, reflecting oxygen atoms attributed to lithium carbonates $\left(\mathrm{Li}_{2} \mathrm{CO}_{3}\right)$ and oxalates remains the major component. Concerning the thirtieth charge, even if we observe again the 01 component characteristic of the material, those relative $(02,03,04)$ to the SEI are still present (note that it was necessary to introduce a very low intensity 04 component (at $534.6 \mathrm{eV}$ ) to fit the experimental curve even if the latter is not precisely attributed). If the intensity of the $\mathrm{O} 2$ component decreases in agreement with the dissolution of the lithium carbonate, the component $\mathrm{O} 3$ relative to PEO and/or ROLi increases (Table 2 and Table 6) compared with the first charge (or the 10th). Note that for this last specie (ROLi), the valence band analysis at the end of the 30th discharge can be useful for a definite attribution. Fig. 7 presents the valence bands of lithium carbonates $\left(\mathrm{Li}_{2} \mathrm{CO}_{3}\right)$, methyl carbonates $\mathrm{CH}_{3} \mathrm{OCO}_{2} \mathrm{Li}$ (for references) and $\mathrm{V}_{2} \mathrm{O}_{5}$ at the end of the thirtieth discharge. Even if the spectrum of $\mathrm{CH}_{3} \mathrm{OCO}_{2} \mathrm{Li}$ is quite similar to thus of $\mathrm{Li}_{2} \mathrm{CO}_{3}$ three main differences exist: the decrease of the narrow peak at $24.3 \mathrm{eV}$ which is replaced by a shoulder, the appearance of an extra peak at $17.6 \mathrm{eV}$ and a decrease of the intensity ratio of both peaks located at 12.9 and $10.8 \mathrm{eV}$. These last features are identified on the valence band of $\mathrm{V}_{2} \mathrm{O}_{5}$ at the end of the 30th discharge. Indeed, it exhibits some of the characteristics described below, and allows us to affirm that ROLi is mixed with $\mathrm{Li}_{2} \mathrm{CO}_{3}$ species. We can conclude to the presence of ROLi species at the surface, which accumulates over cycles, even if the $\mathrm{C}$ 1s core peak analysis reflects an interface mainly dominated by $\mathrm{Li}_{2} \mathrm{CO}_{3}$. Oxalates, PEO and ROLi species do not dissolve as well as lithium carbonates and constitute the main part of the interface at the end of the charge. Note that at the end of the 30th charge, the valence spectrum is characteristic of the electrode material. We can remind that a photoelectron issued from a core level, characterized by an important binding energy, has a lower kinetic energy than that of a valence electron slightly linked. Then, valence electrons come from a more important depth than core electrons. Consequently, the valence bands are more representative of the bulk, while the core peaks are characteristic of the extreme surface composition. Thus, the residual deposit at the end of the charge would be very thin and the valence band is dominated by the signature of $\mathrm{V}_{2} \mathrm{O}_{5}$.

The topography of $\mathrm{V}_{2} \mathrm{O}_{5}$ thin film at the end of the 10th and the 30th discharge (Fig. 8a) is very similar to the one for the first cycle. As for the first discharge, the $\mathrm{V}_{2} \mathrm{O}_{5}$ plates are no more identified, in agreement with the weak percentage of the vanadium and the oxygen (from the material) atoms at the surface. The interfacial layer is predominantly constituted by lithium carbonate species and aggregates are prominent (Fig. 8a). At the end of the 10th charge (Fig. 8c) plates of the crystallized thin film are recovered. Therefore, the formation/dissolution process during cycling is also highlighted by AFM. However, the thickness of plate sides increases during cycling (Table 4). Indeed, it goes from $80 \mathrm{~nm}$ for the as-deposited thin film, 100 at the end of the first charge to $110 \mathrm{~nm}$ at the end of the 10 th charge. 
Furthermore, for the same stages, the Rq parameter decreases from 161, 136 and $125 \mathrm{~nm}$. Then, as the thickness of plate sides increases and the roughness decreases during cycling, the dissolution phenomenon appears less and less effective, the thickness of the SEI at the end of charge increasing. During discharges, it seems therefore that the SEI tends to cover zones left vacant during charges due to successive partial dissolutions and leads to the formation of prominent aggregates. For the 30th charge (Fig. 8d), the dimension of plate sides is about $130 \mathrm{~nm}$ (the residual deposit increases) and the $\mathrm{Rq}$ parameter is equal to $115 \mathrm{~nm}$. The interfacial layer at the end of charge becomes more and more thick in agreement with XPS results. On the whole, the main chemical modifications during the cycling appear between the tenth and 30th cycle, whether it comes from the degradation of the redox process or the evolution of the interfacial layer nature after the charge. Concerning the morphology, similar conclusions can be drawn, because the thickness of plate sides increases in a more significant way between the 10th and 30th charge than between the first and the tenth charge. All these results are coherent with the evolution of the capacity on the first 30 cycles.

\section{Conclusion}

During the first cycle, the growth of a surface layer between the $\mathrm{V}_{2} \mathrm{O}_{5}$ positive electrode and the liquid electrolyte has been evidenced upon the discharge as well as its partial dissolution upon the charge by (quantitative and qualitative) XPS and AFM analyses. This layer mainly consists of $\mathrm{Li}_{2} \mathrm{CO}_{3}$ aggregates during the discharge which recover totally the $\mathrm{V}_{2} \mathrm{O}_{5}$ surface. The AFM image at the end of the discharge displays aggregates of such species and the disappearance of the typical tangled plates of the as deposited sample. At the end of the first charge, $\mathrm{C}$ 1s and $\mathrm{O} 1 \mathrm{~s}$ XPS core peaks confirm the dissolution of $\mathrm{Li}_{2} \mathrm{CoO}_{3}$ species. However, a very thin residual deposit of ROLi, PEO and oxalates remains on surface and the typical plates of $\mathrm{V}_{2} \mathrm{O}_{5}$ covered by a thin layer are identified by AFM. Then, beyond the partial reversibility of the redox process evidenced by XPS, the loss of capacity noticed at the end of the first galvanostatic cycle could be also explained by the SEI formation/partial dissolution and by the partial reversibility of the redox process.

During cycling, XPS quantitative analysis exhibits an increase of the residual deposit as the percentage of vanadium decreases at the end of the various charges. $\mathrm{Li}_{2} \mathrm{CO}_{3}$ species are dissolving but a residual deposit more and more thick remains on surface. It tends to accumulate during cycles and induces an increase of the thickness of the plate sides characteristic of the pristine material. Then, concomitant to the degradation of the redox processes during cycling, the chemical and morphological changes of the SEI layer allow to explain the evolution of the discharge capacity over cycles. It is one of the first combined study using XPS and AFM that clearly evidences the formation/dissolution process of a passivation layer SEI-like on $\mathrm{V}_{2} \mathrm{O}_{5}$ thin films and shows the complex composition evolution of such 
layer. Even if some models have been already proposed to explain the formation of $\mathrm{Li}_{2} \mathrm{CO}_{3}$ species, some additional work has to be done to better understand the mechanisms at the origin of chemical interactions between positive electrode and liquid electrolyte.

\section{References}

[1] J.B. Bates, N.J. Dudney, D.C. Lubben, G.R. Gruzalski, B.S. Kwak, Xiahua Yu and R.A. Zuhr, J. Power Sources 54 (1995), pp. 58-62.

[3] J.L. Souquet and M. Duclot, Solid State Ionics 148 (2002), pp. 375-379.

[4] S. Koike, T. Fujieda, T. Sakai and S. Higuchi, J. Power Sources 81-82 (1999), pp. 581-584.

[5] D.B. Le, S. Passerini, J. Guo, J. Ressler, B.B. Owens and W.H. Smyrl, J. Electrochem. Soc. 142 (6) (1995), pp. 102-103.

[6] A. Tranchant, R. Messina and J. Perrichon, J. Electroanal. Chem. 113 (1980), p. 225.

[7] A. Mantoux, H. Groult, E. Balnois, P. Doppelt and L. Gueroudji, J. Electrochem. Soc. 151 (2004), p. A368.

[8] K. West, B. Zachau-Christiansen, S. Skaarup and F.W. Poulsen, Solid State Ionics 57 (1992), p. 41.

[9] H.Y. Park and W.H. Smyrl, J. Electrochem. Soc. 141 (1994), p. L25.

[10] A. Gies, B. Pecquenard, A. Benayad, H. Martinez, D. Gonbeau, H. Fuess and A. Levasseur, Solid State Ionics 176 (17-18) (2005), p. 1627.

[11] A. Benayad, H. Martinez, A. Gies, B. Pecquenard, A. Levasseur and D. Gonbeau, J. Phys. Chem. Solids 67 (2006), pp. 1320-1324.

[12] D. Aurbach, J. Electrochem. Soc. 136 (1989), p. 1610.

[13] K. Kanamura, H. Takezawa, S. Shiraiski and Z. Takehara, J. Electrochem. Soc. 144 (1997), p. 1900.

[14] D. Aurbach, J. Power Sources 89 (2006), p. 209.

[15] A. Benayad, H. Martinez, A. Gies, B. Pecquenard, A. Levasseur and D. Gonbeau, J. Electron Spectrosc. Relat. Phenom. 150 (1) (2006), pp. 1-10.

[16] Y.S. Cohen and D. Aurbach, Electrochem. Commun. 6 (2004), pp. 536-542.

[17] J. Swiatowska-Mrowiecka, V. Maurice, S. Zanna, L. Klein, E. Briand, I. Vickridge and P. Marcus, J. Power Sources 170 (2007), pp. 160-172.

[18] C. Delmas, H. Cognac-Auradou, J.M. Cocciantelli, M. Menetrier and J.P. Doumerc, Solid State Ionics 69 (1994), p. 257.

[19] J. Galy, J. Solid State Chem. 100 (1992), p. 229.

[20] K. West, B. Zachau-Christiansen, T. Jacobsen and S. Skaarup, Solid State Ionics 76 (1995), p. 15.

[21] R. Fong, U. Von Sacken and J.R. Dahn, J. Electrochem. Soc. 137 (1990) (2009).

[22] D. Aurbach, M.L. Daroux, P.W. Faguy and E. Yeager, J. Electrochem. Soc. 134 (1987), pp. 16111620.

[23] D. Aurbach, Y. Ein-Eli, B. Markovsky, A. Zaban, S. Luski, Y. Carmeli and H. Yamin, J. Electrochem. Soc. 142 (1995), pp. 2882-2889.

[24] S. Laruelle, S. Pilard, P. Guenot, S. Grugeon and J.M. Tarascon, J. Electrochem. Soc. 151 (2004), 
pp. $1202-1209$.

[25] R. Dedryvère, S. Laruelle, S. Grugeon, L. Gireaud, J.-M. Tarascon and D. Gonbeau, J. Electrochem. Soc. 152 (2005), pp. A689-A696.

[26] M.-H. Lindic, H. Martinez, A. Benayad, B. Pecquenard, P. Vinatier, A. Levasseur and D. Gonbeau, Solid State Ionics 176 (17-18) (2005), pp. 1529-1537. 
Figures
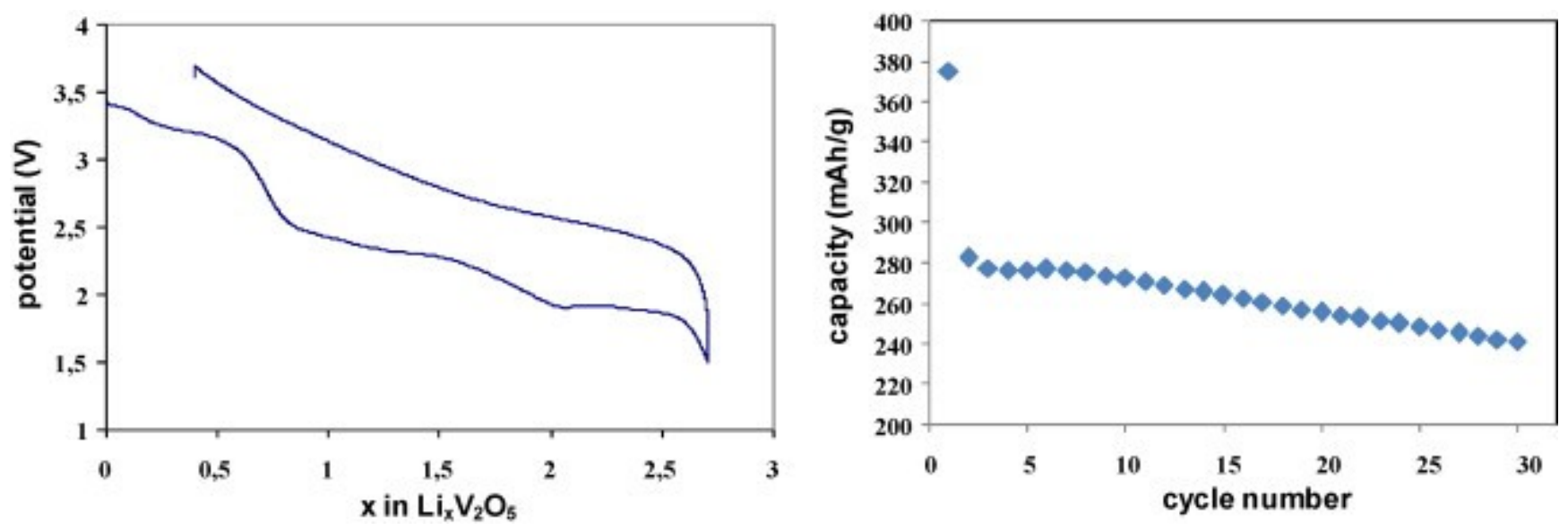

Fig. 1. The first galvanostatic cycle (a) and the discharge capacity evolution as a function of cycles number (b). The applied current density is $20 \mu \mathrm{A} \mathrm{cm}{ }^{-2}$ between 1.5 and $3.7 \mathrm{~V} / \mathrm{Li}$.

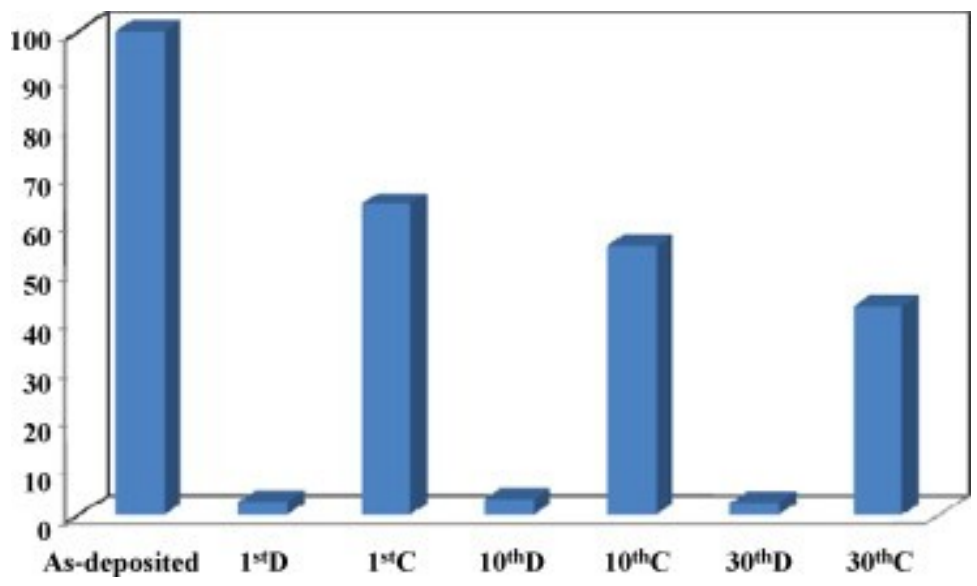

Fig. 2. Relative atomic percentage of vanadium determined from the XPS quantitative analyses performed before the mechanical erosion on $\mathrm{V}_{2} \mathrm{O}_{5}$ thin film. $100 \%$ correspond to approximately $25 \%$ of the vanadium amount in each sample and the scale is proportional to the vanadium amount that decreases during the discharge and increases during the charge. 
(a) $\mathrm{Ols}$

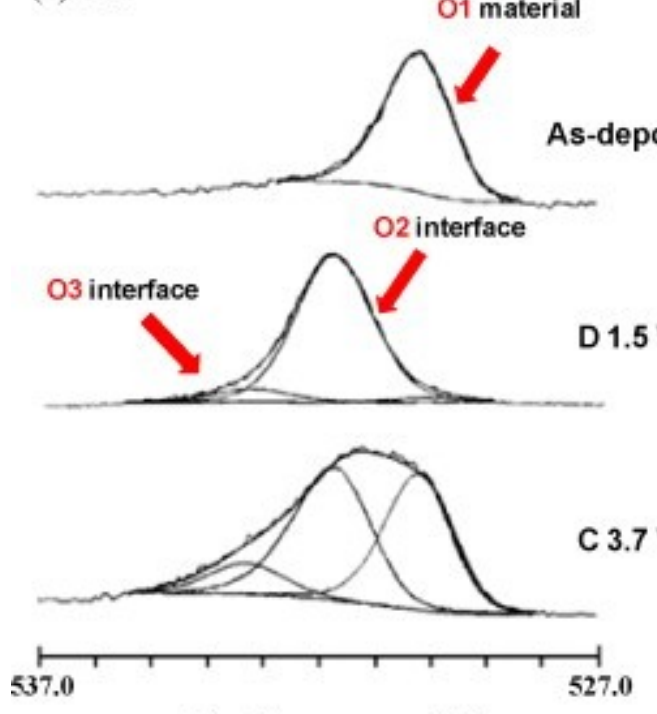

Binding energy (eV) (b) $\mathrm{Cls}$

$\mathrm{C} 2: \mathrm{C}-\mathrm{O}$ C1 contamination

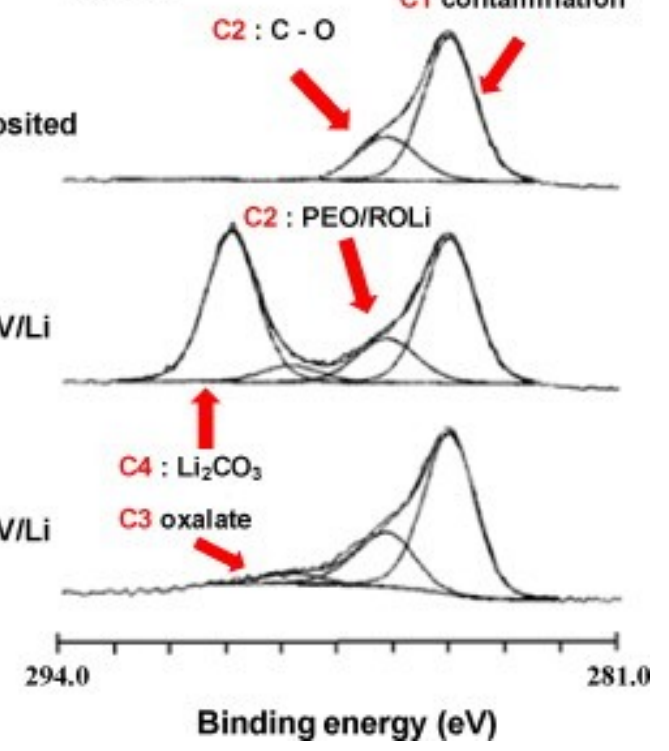

Fig. 3. XPS analyses of the $O$ 1s (a) and C 1s (b) core peaks performed before mechanical erosion onto $\mathrm{V}_{2} \mathrm{O}_{5}$ thin films at different stages of the first cycle: the as-deposited sample, at the end of the discharge $(\mathrm{V}=1.5 \mathrm{~V} / \mathrm{Li})$ and at the end of the charge $(\mathrm{C}=3.7 \mathrm{~V} / \mathrm{Li})$.
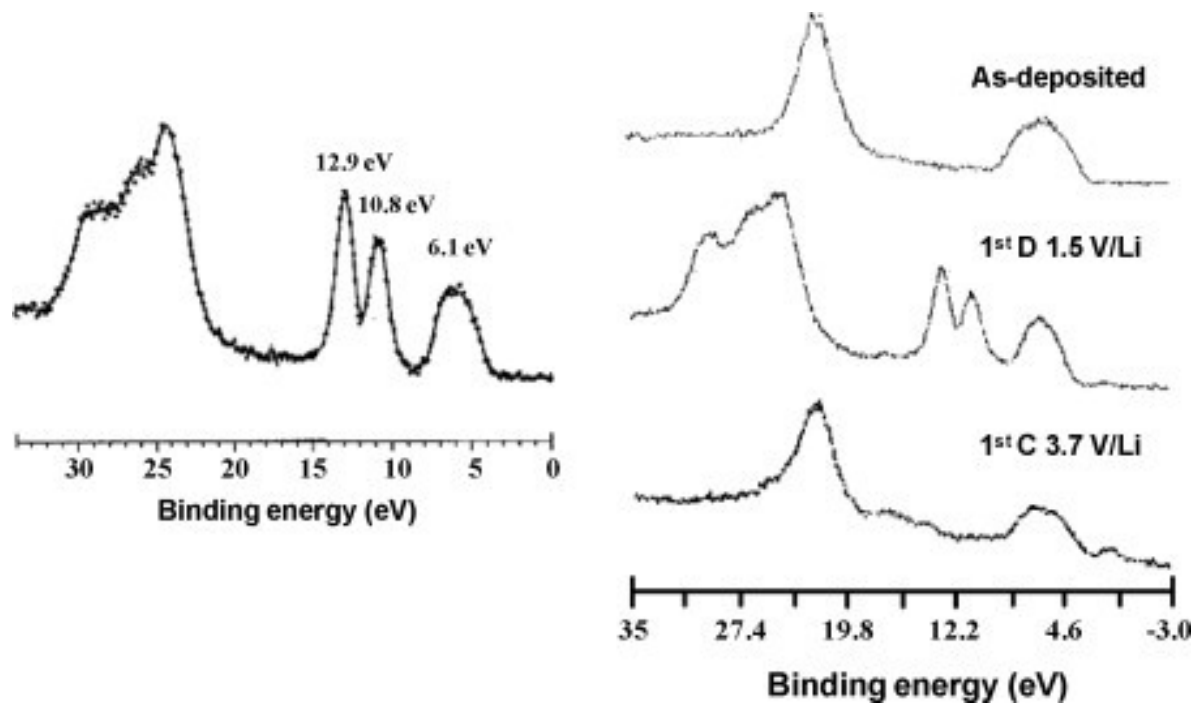

Fig. 4. XPS valence bands of $\mathrm{Li}_{2} \mathrm{CO}_{3}$ as reference, of the as deposited $\mathrm{V}_{2} \mathrm{O}_{5}$ thin film, at the end of the discharge $(\mathrm{V}=1.5 \mathrm{~V} / \mathrm{Li})$ and at the end of the charge $(\mathrm{C}=3.7 \mathrm{~V} / \mathrm{Li})$. 

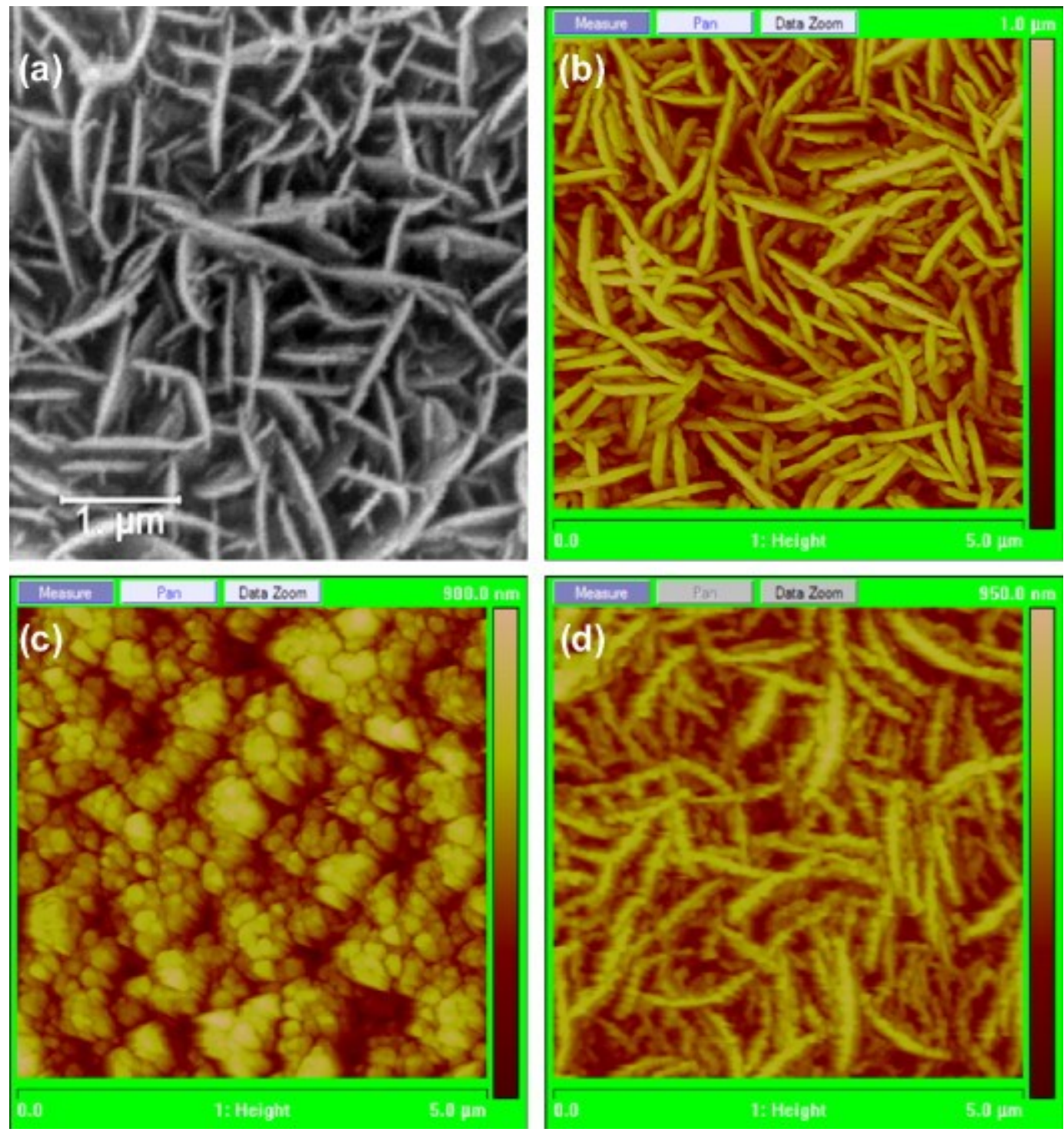

Fig. 5. SEM picture of the as-deposited thin film (a) and AFM images of the pristine vanadium pentoxide thin films (b) at the end of the 1st discharge (c) and at the end of the 1st charge (d). 


\section{C2: PEO/ROLi}

(a) $\mathrm{C} 1 \mathrm{~s}$

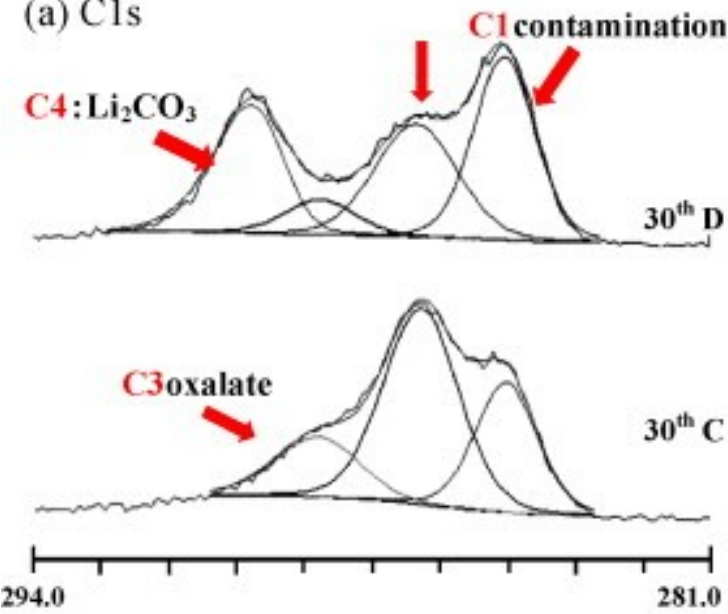

Binding energy $(\mathrm{eV})$ (b) O1s
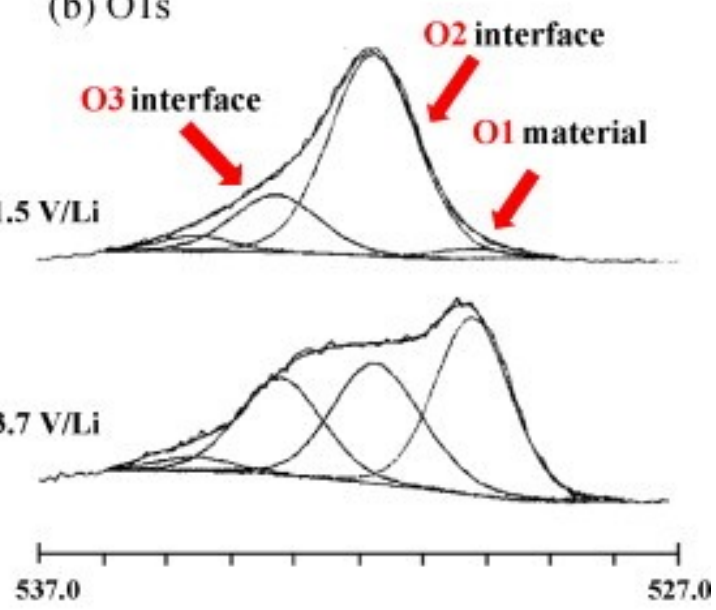

Binding energy $(\mathrm{eV})$

Fig. 6. XPS analyses of the $\mathrm{O} 1 \mathrm{~s}$ (a) and $\mathrm{C}$ 1s (b) core peaks performed before mechanical erosion onto $\mathrm{V}_{2} \mathrm{O}_{5}$ thin film at the end of the 30th discharge $(\mathrm{V}=1.5 \mathrm{~V} / \mathrm{Li})$ and at the end of the 30th charge $(\mathrm{C}=3.7 \mathrm{~V} / \mathrm{Li})$.

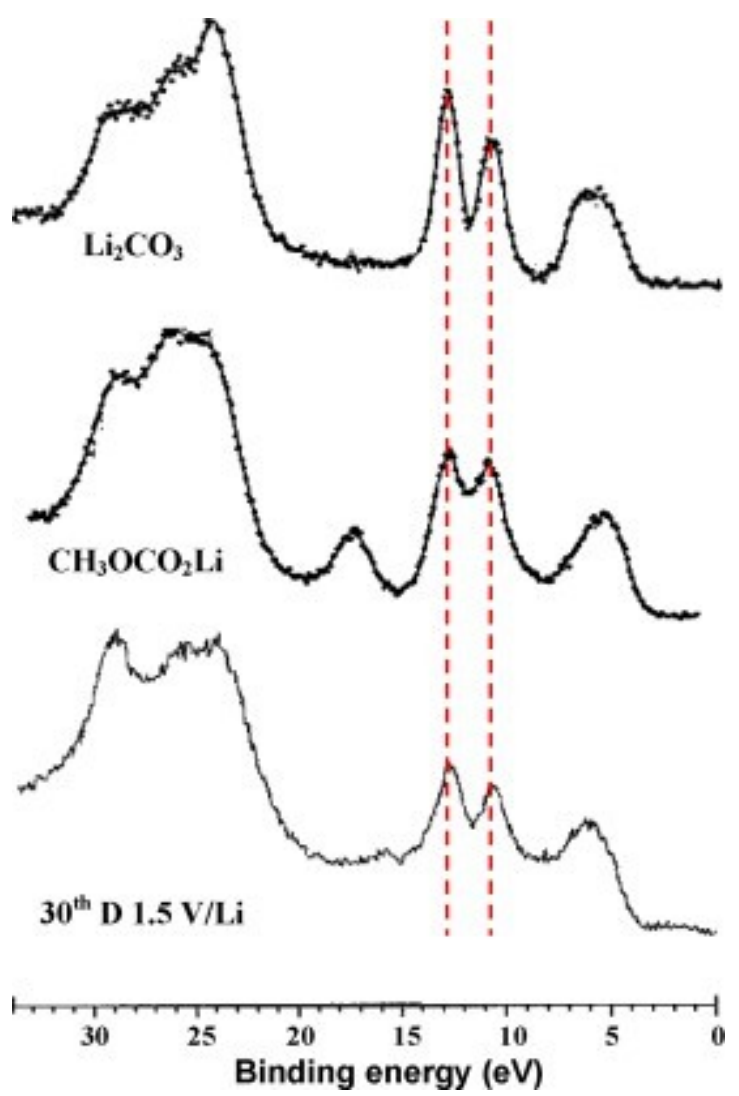

Fig. 7. XPS valence bands of $\mathrm{Li}_{2} \mathrm{CO}_{3}$ and $\mathrm{CH}_{3} \mathrm{CO}_{2} \mathrm{OLi}$ as references, and for $\mathrm{V}_{2} \mathrm{O}_{5}$ thin film at the end of the 30th discharge $(\mathrm{V}=1.5 \mathrm{~V} / \mathrm{Li})$. 

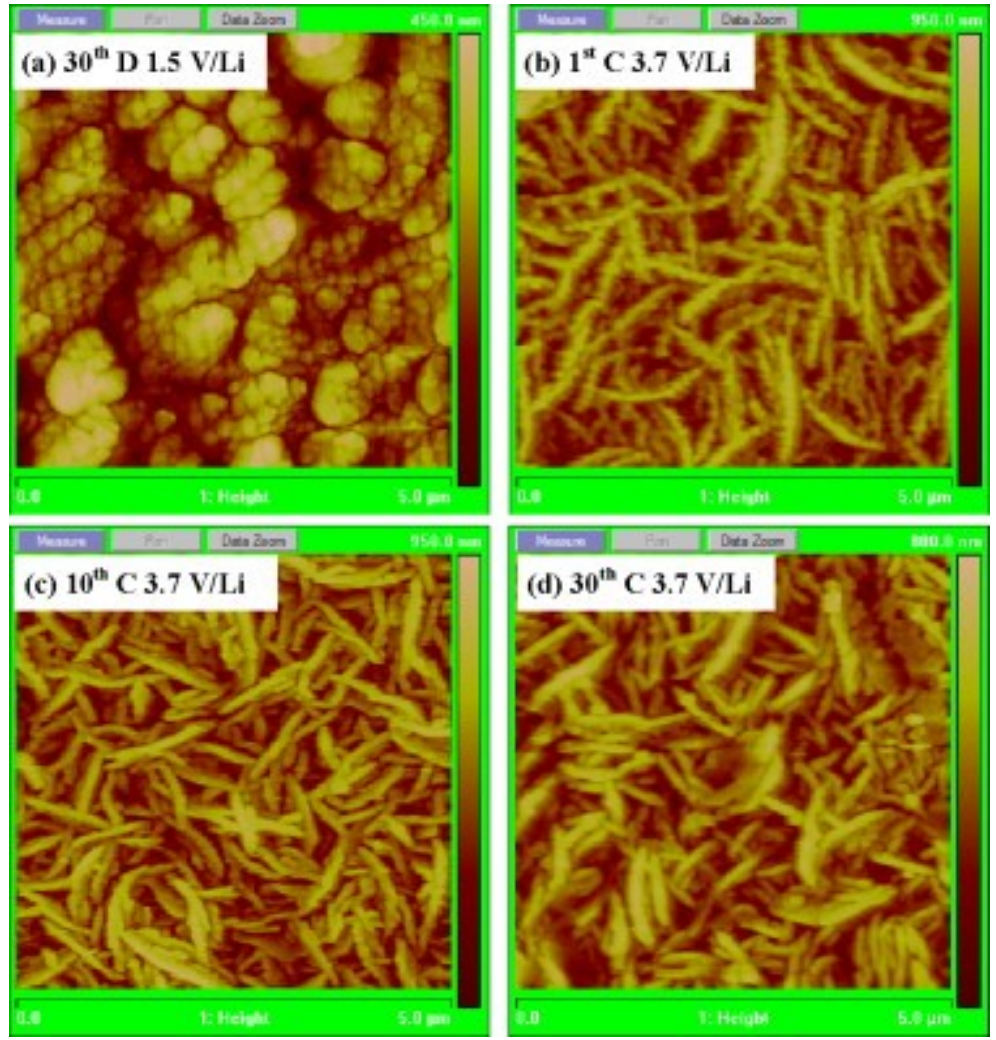

Fig. 8. AFM images of $\mathrm{V}_{2} \mathrm{O}_{5}$ at the end of the 30th discharge $(\mathrm{V}=1.5 \mathrm{~V} / \mathrm{Li})(\mathrm{a})$, and at the end of the 1st (b), 10th (c), 30th (d) charges $(\mathrm{C}=3.7 \mathrm{~V} / \mathrm{Li})$. 
Tables

Table 1.

XPS V $2 \mathrm{p}_{3 / 2}$ binding energies (eV) in $\mathrm{V}_{2} \mathrm{O}_{5}$ thin film (after mechanical erosion) at the end of the 1st, 10th, 30th discharges and charges

\section{Potential (V/Li) $\mathrm{V}^{5+} 2 \mathrm{p}_{3 / 2}(\mathrm{eV}) \quad \mathrm{V}^{4+} 2 \mathrm{p}_{3 / 2}(\mathrm{eV}) \quad \mathrm{V}^{3+} 2 \mathrm{p}_{3 / 2}(\mathrm{eV})$}

\begin{tabular}{llll}
\hline As-deposited & $517.4-(1.2)-100 \%$ & & \\
1 st $D 1.5 \mathrm{~V} / \mathrm{Li}$ & $517.4-(1.4)-26 \%$ & $516.2-(1.4)-46 \%$ & $515.1-(1.4)-28 \%$ \\
1 st $C 3.5 \mathrm{~V} / \mathrm{Li}$ & $517.4-(1.4)-66 \%$ & $516.2-(1.4)-34 \%$ & \\
10 th $D 1.5 \mathrm{~V} / \mathrm{Li}$ & $517.4-(1.4)-32 \%$ & $516.3-(1.4)-40 \%$ & $515.1-(1.4)-28 \%$ \\
10 th $C 3.5 \mathrm{~V} / \mathrm{Li}$ & $517.4-(1.4)-61 \%$ & $516.2-(1.4)-39 \%$ & \\
30th $D 1.5 \mathrm{~V} / \mathrm{Li}$ & $517.4-(1.3)-28 \%$ & $516.3-(1.3)-51 \%$ & $515.3-(1.3)-21 \%$ \\
30th $C 3.5 \mathrm{~V} / \mathrm{Li}$ & $517.4-(1.4)-57 \%$ & $516.2-(1.4)-43 \%$ &
\end{tabular}

The relative percentages of the different oxidation degrees are indicated as well as the full width at half maximum values in parentheses.

Table 2.

XPS $\mathrm{O} 1 \mathrm{~s}$ binding energies $(\mathrm{eV})$ in as-deposited $\mathrm{V}_{2} \mathrm{O}_{5}$ thin film (before mechanical erosion) during the first cycle, at the end of the discharge $(D 1.5 \mathrm{~V} / \mathrm{Li})$ and at the end of the charge $(C 3.7 \mathrm{~V} / \mathrm{Li})$

\begin{tabular}{lll}
\hline \multicolumn{1}{c|}{ Potential (V/Li) } & O 1s (eV) & O (\%) \\
\cline { 1 - 2 } As-deposited & O1 530.2-(1.4)-100\% & 42 \\
& & \\
1 st D 1.5 V/Li & O1 530.2-(1.4)-2\% & 1.1 \\
& O2 531.8-(1.6)-90\% & 40.8 \\
& O3 533.3-(1.6)-8\% & 3.6
\end{tabular}

1 st $C 3.5 \mathrm{~V} / \mathrm{Li} \quad$ O1 530.2-(1.4)-42\% 20.4

O2 531.8-(1.6)-48\% 23.3

O3 533.3-(1.6)-10\% 5.2 
48.9

The relative percentages of the different $\mathrm{O} 1 \mathrm{~s}$ components are indicated as well as the full width at half maximum values in parentheses. The last column indicates the total oxygen percentage within the material.

\section{Table 3.}

XPS C 1s binding energies (eV) in as-deposited $\mathrm{V}_{2} \mathrm{O}_{5}$ thin film (before mechanical erosion) at the end of the 1st discharge $(D 1.5 \mathrm{~V} / \mathrm{Li})$ and at the end of the 1 st charge $(C 3.7 \mathrm{~V} / \mathrm{Li})$

\section{Potential (V/Li) C 1s (eV) C (\%)}

\begin{tabular}{lll}
\hline As-deposited & C1 285.0-(1.4)-90\% & 24.9 \\
& C2 286.5-(1.6)-10\% & 2.8
\end{tabular}

1 st $D 1.5 \mathrm{~V} / \mathrm{Li} \quad \mathrm{C} 1285.0-(1.4)-40 \% \quad 10.1$

C2 286.5-(1.6)-14\% 3.6

C3 288.7-(1.6)-5\% 1.3

C4 290.1-(1.4)-41\% 10.5

1 st $C 3.5 \mathrm{~V} / \mathrm{Li} \quad$ C1 285.0-(1.4)-68\% 25.4

C2 286.5-(1.6)-27\% 10.0

C3 288.7-(1.6)-5\% 2.0

37.4

The relative percentages of the different $\mathrm{C} 1 \mathrm{~s}$ components are indicated as well as the full width at half maximum values in parentheses. The last column indicates the total carbon percentage within the material. 
ICMCB / IPREM @ 2008

Table 4.

Thickness of plate sides and Rq parameter during cycling: at the end of the 1st, 10th, 30th discharges and charges

\section{Potential (V/Li) Average thickness of plates sides (nm) $\pm 2 \quad \mathrm{Rq}(\mathrm{nm})$}

\begin{tabular}{lll}
\hline As-deposited & 80 & 160 \\
1 st $D 1.5 \mathrm{~V} / \mathrm{Li}$ & & 130 \\
1 st $C 3.5 \mathrm{~V} / \mathrm{Li}$ & 100 & 136 \\
10 th $D 1.5 \mathrm{~V} / \mathrm{Li}$ & & 75 \\
10 th $C 3.5 \mathrm{~V} / \mathrm{Li}$ & 110 & 125 \\
30 th $D 1.5 \mathrm{~V} / \mathrm{Li}$ & & 50 \\
30 th $C 3.5 \mathrm{~V} / \mathrm{Li}$ & 130 & 115 \\
\hline
\end{tabular}

\section{Table 5 .}

XPS C 1s binding energies (eV) in as-deposited $\mathrm{V}_{2} \mathrm{O}_{5}$ thin film (before mechanical erosion) at the end of the 30th discharge $(D 1.5 \mathrm{~V} / \mathrm{Li})$ and at the end of the 30 th charge $(C 3.7 \mathrm{~V} / \mathrm{Li})$.

Potential (V/Li) C 1s (eV) C (\%)

$\begin{array}{lll}\text { As-deposited } & \text { C1 285.0-(1.4)-90\% } & 24.9 \\ & \text { C2 286.5-(1.6)-10\% } & 2.8\end{array}$

30th $D$ 1.5 V/Li $\quad$ C1 285.0-(1.4)-35.0\% 11.6

C2 286.5-(1.6)-28.9\% 9.6

C3 288.6-(1.6)-7.8\% 2.6

C4 290.0-(1.5)-28.3\% 9.4

30th $C 3.5 \mathrm{~V} / \mathrm{Li} \quad$ C1 285.0-(1.4)-34.8\% 9.3

C2 286.5-(1.7)-45.0\% 11.8 
The relative percentages of the different $\mathrm{C}$ 1s components are indicated as well as the full width at half maximum values in parentheses. The last column indicates the total carbon percentage within the material.

\section{Table 6.}

XPS $\mathrm{O} 1 \mathrm{~s}$ binding energies $(\mathrm{eV})$ in as-deposited $\mathrm{V}_{2} \mathrm{O}_{5}$ thin film (before mechanical erosion) at the end of the 30 th discharge $(D 1.5 \mathrm{~V} / \mathrm{Li})$ and at the end of the 30 th charge $(C 3.7 \mathrm{~V} / \mathrm{Li})$

Potential (V/Li) O 1s (eV) O

As-deposited O1 530.2-(1.4)-100\% 42

30th $D$ 1.5 V/Li $\quad$ O1 530.2-(1.4)-3\% $\quad 1.2$

O2 531.7-(1.6)-70\% 31.5

O3 533.2-(1.6)-22\% 9.5

O4 534.6-(1.4)-5\% $\quad 2.4$

30th $C 3.5 \mathrm{~V} / \mathrm{Li} \quad$ O1 530.2-(1.4)-40\% 17.3

O2 531.7-(1.6)-31\% 13.4

O3 533.2-(1.6)-24\% 10.3

O4 534.6-(1.4)-5\% 2.2

The relative percentages of the different $\mathrm{O} 1 \mathrm{~s} \mathrm{components}$ are indicated as well as the full width at half maximum values in parentheses. The last column of right-hand side indicates the total oxygen percentage within the material. 